Proc. Estonian Acad. Sci. Eng., 2004, 10, 4, 270-280

\title{
Advanced dynamic models for evaluation of accuracy of machining on lathes
}

\author{
Gennady Aryassov $^{\mathrm{a}}$, Tauno Otto ${ }^{\mathrm{b}}$ and Svetlana Gromova ${ }^{\mathrm{a}}$ \\ a Department of Mechatronics, Tallinn University of Technology, Ehitajate tee 5, 19086 Tallinn, \\ Estonia; garjasov@staff.ttu.ee \\ b Department of Machinery, Tallinn University of Technology, Ehitajate tee 5, 19086 Tallinn, \\ Estonia; tauno@staff.ttu.ee \\ Received 1 July 2004, in revised form 8 September 2004
}

\begin{abstract}
This paper describes the influence of lathe vibrations on the accuracy and roughness of machined parts. The calculation schemes involve systems with one and two degrees of freedom, representing vibrations of the blank as a rigid body, hinged in the spindle and elastically supported in the tailstock of the lathe. Experimental measurements were performed on lathes of type 1K62 at different cutting speeds, feeds and depths of cut. The analysis of roughness measurement data confirmed the accuracy of the proposed calculation model. Surface roughness parameters of the blank satisfactorily agreed with the corresponding data of the theoretical investigation. To study the influence of gyroscopic forces on the surface roughness, the calculation model with two degrees of freedom was used. The results of experimental and theoretical investigations coincided satisfactorily.
\end{abstract}

Key words: lathe, vibration, calculation model, natural frequency, surface roughness.

\section{INTRODUCTION}

Dynamic phenomena of vibrations are caused by external factors on the strained system of the lathe. In the turning operations, tool vibrations influence both product quality and productivity and may also have a negative influence on the working environment $\left[{ }^{1}\right]$. During machining of a material, all disturbances finally lead to relative displacements of the cutter and the blank. It allows us to link the parameters of surface roughness to the relative vibrodisplacements of the cutter and the blank $\left.{ }^{2}\right]$. In the calculation of dynamic characteristics, the real elastic system of the lathe was replaced by a system with finite degrees of freedom. In the case of insufficient accuracy of the underlying data, complicated 
calculation schemes can lead to significant errors in the calculation $\left[{ }^{3}\right]$. Therefore we used simplified schemes, composed on the basis of experimental investigations.

A system with one degree of freedom, representing the vibration of the blank as a rigid body hinged in the spindle and elastically supported in the tailstock of the lathe, was used as a basis of the calculation scheme. The exact solution of a continuous system, which has an infinite number of degrees of freedom, showed that the first natural frequency of the continuous model is represented by the natural frequency of the accepted model. That permits to use this calculation model for the analysis of vibrations in metal cutting.

Experimental measurements were performed on the lathes of type 1K62 at different cutting speeds, feeds and depths of cut. The experimental results satisfactorily coincide with the corresponding theoretical results in an adequate frequency range. As the frequency increased, discrepancies between theoretical and experimental results widened gradually. As a result, limitations in the use of the proposed mathematical model of the blank on lathe vibration were considered. After every cutting, surface roughness was measured with a profilograph "Surftronic 3+". The analysis of data on roughness measurement confirmed the accuracy of the calculation model. Surface roughness parameters of the blank satisfactorily agreed with the corresponding data of the theoretical investigation. Several studies have been concentrated on cutting tool vibrations during machining $\left[{ }^{4}\right]$ and investigation of forces and contact area for modelling the turning process $\left[^{5}\right]$. Finite element analysis (FEA) is maturing into a promising analysis tool to enhance understanding of machining and for prediction of the machining process output; however, the accuracy of FEA depends on how adequate the selected physical model is $\left[{ }^{6}\right]$.

Modern monitoring and diagnostics methods of technological processes are described in $\left.{ }^{7}\right]$. We used a calculation model with two degrees of freedom to study the influence of gyroscopic forces on the surface roughness. Such an approach to this problem has not been used earlier. The results of experimental and theoretical investigations compared favourably. The results enable us to increase the accuracy of different conditions of cutting. In the future, calculation models with four degrees of freedom will be used. Also, the stability of the blank in the action of the moving cutting force is to be investigated. Finally, it is necessary to derive theoretical formulas, which could help to determine the roughness accurately. The latter would provide a possibility to control and adjust surface roughness by processing.

\section{THEORETICAL ANALYSIS}

To develop a dynamic calculation model, first, we formulated the research problem. In order to simplify the dynamic model, we eliminated the factors, which have a minor effect on the results of the solution. Actually, these models 
have a limited area of application $\left[^{8}\right]$. In this article, dynamic models with one and two degrees of freedom were investigated.

\subsection{Dynamic model with one degree of freedom}

By the idling of the lathe (Fig. 1, a), the differential equation of forced vibrations is as follows

$$
J_{0} \ddot{\varphi}+k_{y} \varphi l^{2}=M_{y} \sin p t,
$$

where $J_{0}$ is the moment of inertia of the blank about the headstock (spindle), $\varphi$ is the declination angle of the blank, $k_{y}$ is the horizontal spring constant of elastic support of the blank, $l$ is the length of the blank, $M_{y}=m p^{2} y_{b} l / 2, \quad m$ is mass of the blank, $p=2 \pi f, f$ is the frequency of the foundation vibrations in $\mathrm{Hz}$ and $y_{b}$ is the amplitude of the foundation vibrations.

We are restricted to steady-state forced vibrations

$$
\varphi=\frac{M_{y}}{J_{0}\left(\omega^{2}-p^{2}\right)} \sin p t
$$

where $\omega=\sqrt{k_{y} l^{2} / J_{0}}$ is the natural frequency of the lathe system.

From the above, the relative velocity of the forced vibrations of the blank is

$$
v=\dot{y}=\dot{\varphi} l=\frac{p M_{y}}{J_{0}\left(\omega^{2}-p^{2}\right)} \cos p t .
$$

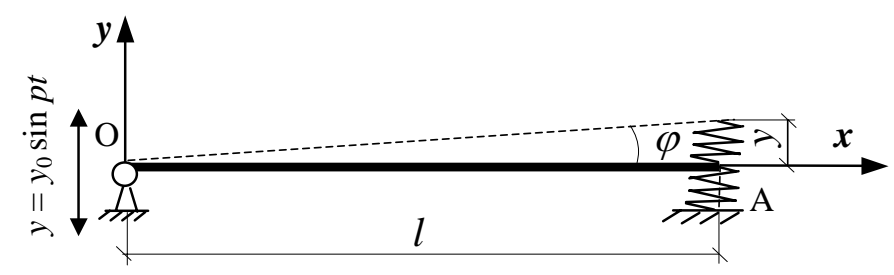

(a)

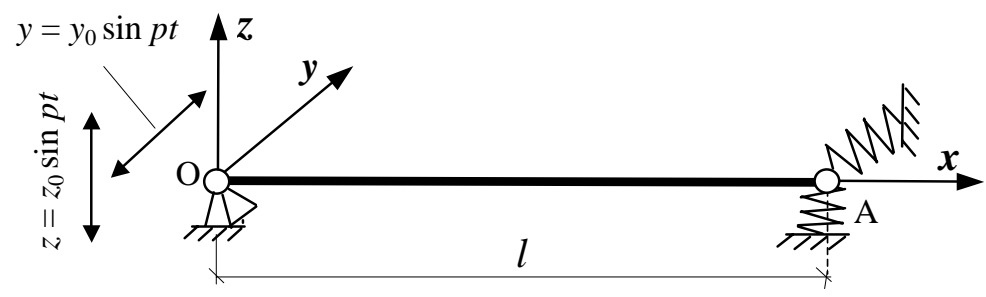

(b)

Fig. 1. Dynamic models with one (a) and two (b) degrees of freedom. 

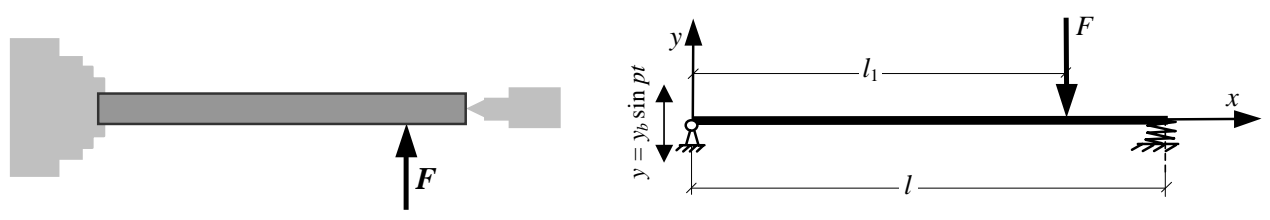

Fig. 2. Calculation schema in cutting.

The accuracy of the accepted calculation model is verified by comparing theoretical and experimental results. In machining of the part on the lathe, the cutting force $F$ (Fig. 2) is not constant. It is determined by many factors as the change in the thickness of the cut-off chips, the change in the mechanical properties of the blank material and the tool wear. The input of the lathe system is the cutting force $F$ as a function of time and the output is the displacement of the cutter or the blank (Fig. 2).

The differential equation of forced vibrations caused by the cutting force $F$ is

$$
J_{0} \ddot{\varphi}+k_{y} \varphi l^{2}=M_{y} \sin p t+\left(F_{r}+F_{a} \cos \omega^{*} t\right) l_{1},
$$

where the cutting force $F$ is reproduced as a sum of the following items: the constant component $F_{r}$ determined in practice by a simplified empirical formula $\left.{ }^{2}\right]$ and the variable component $F_{a} \cos \omega^{*} t$ ( $l_{1}$ is the coordinate of the cutting force). The amplitude of the variable component of the cutting force is related to the roughness and varies in a rather wide range.

The solution of Eq. (4) can be expressed in the form of the displacement of the blank end in relation to initial conditions $y_{0}$ and $v_{0}$

$$
\begin{aligned}
y=\varphi l= & \left(y_{0}-F_{0} l_{1}-E l_{1} l\right) \cos \omega t+\left(\frac{v_{0}-D l p}{\omega}\right) \sin \omega t \\
& +D l \sin p t+F_{0} l_{1}+E l l_{1} \cos \omega^{*} t,
\end{aligned}
$$

whereas the velocity of motion $v$ is

$$
\begin{aligned}
& v=-\left(y_{0}-F_{0} l_{1}-E l l_{1}\right) \omega \sin \omega t \\
& +\left(v_{0}-D l p\right) \cos \omega t+D l p \cos p t-E l l_{1} \omega^{*} \sin \omega^{*} t, \\
& D=\frac{M_{y}}{J_{0}\left(\omega^{2}-p^{2}\right)}, \quad F_{0}=\frac{F_{r}}{k l}, \quad E=\frac{F_{a}}{J_{0}\left(\omega^{2}-\omega^{* 2}\right)} .
\end{aligned}
$$

With regard to resistance forces, the solution was obtained in the similar way. However, it is not presented here because it is massive. 


\subsection{Dynamic model with two degrees of freedom}

Such a model (Figs. 1, b and 3) enables us to take into account the effect of the gyroscopic forces, resulting from the rotation of the blank.

The differential equations of forced vibrations, caused by the cutting force $F$, according to the theorem about the kinetic moment are presented in the following form

$$
\begin{aligned}
& J_{0} \ddot{z}-A \omega_{b} \dot{y}+k_{z} z l^{2}=M_{z} \sin p t, \\
& J_{0} \ddot{y}+A \omega_{b} \dot{z}+k_{y} y l^{2}=M_{y} \cos p t+F_{r} l_{1}+F_{a} l_{1} \cos \omega^{*} t,
\end{aligned}
$$

where $\omega_{b}$ is the angular velocity of the rotation of the blank, $M_{z}=m p^{2} z_{b} l / 2$, $y_{b}$ and $z_{b}$ are an amplitudes of the foundation vibrations, $k_{z}$ and $k_{y}$ are spring constants, $A$ is the moment of inertia of the blank relative to the axis of rotation. The general solution of Eq. (8) represents free vibrations

$$
\begin{aligned}
& y_{1}=a_{1} \sin \left(p_{1} t+\alpha_{1}\right)+a_{2} \sin \left(p_{2} t+\alpha_{2}\right), \\
& z_{1}=\mu_{1} a_{1} \sin \left(p_{1} t+\alpha_{1}\right)+\mu_{2} a_{2} \sin \left(p_{2} t+\alpha_{2}\right),
\end{aligned}
$$

where $a_{1}, a_{2}, \alpha_{1}$ and $\alpha_{2}$ are constants of integration to be determined from the initial conditions, $\mu_{1}$ and $\mu_{2}$ are ratios of the amplitudes of the two principal modes of vibrations, $p_{1}$ and $p_{2}$ are the natural frequencies of vibrations with gyroscopic forces

$$
p_{1,2}=\sqrt{\left(b^{2} \pm \sqrt{b^{2}-4 J_{0}{ }^{2} l^{4} k_{y} k_{z}}\right) 0.5 J_{0}},
$$

where

$$
b=J_{0} l^{2}\left(k_{y}+k_{z}\right)+A^{2} \omega_{b}^{2} .
$$

Our analysis shows that with an increase in the value of $\omega_{b}$, the difference between the higher and the lower frequencies, $p_{1}$ and $p_{2}$, is increased (Fig. 4).

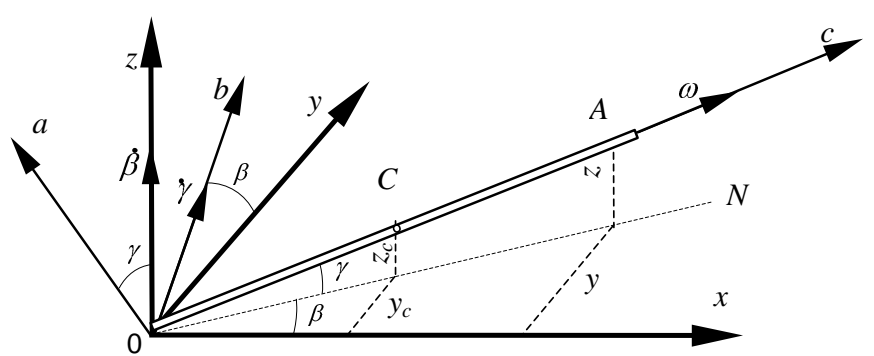

Fig. 3. Gyroscope system with two degrees of freedom in cutting. 

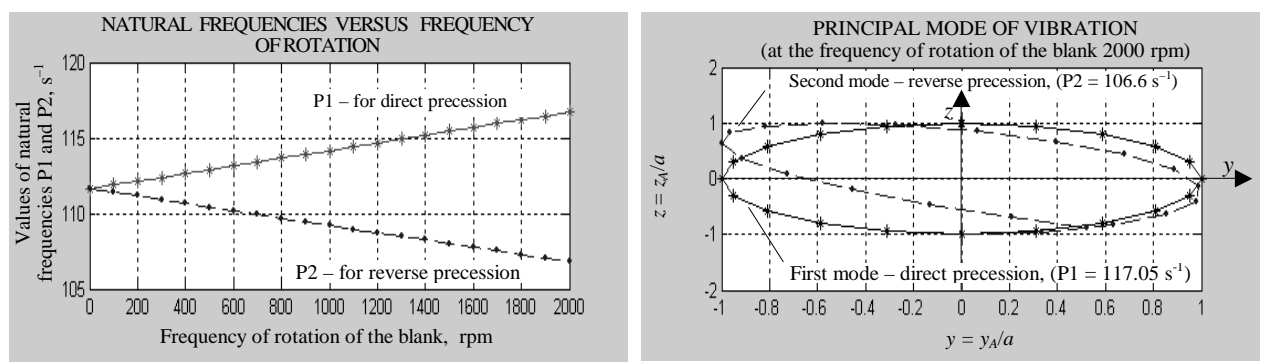

Fig. 4. Principal modes of vibration with gyroscopic forces, corresponding to two different natural frequencies; $a$ - amplitude of the principal mode of vibration.

It was found that for the first mode with the higher frequency $p_{1}$, the ratio $\mu_{1}$ was positive, i.e., the vibrations $y_{1}$ and $z_{1}$ were in phase or in the so-called direct precession. For the lower frequency $p_{2}$, the vibrations $y_{2}$ and $z_{2}$ were in the opposite phase or in the so-called reverse precession.

In the first mode of vibration, a point of the blank axis moves on the circle in the direction of its own rotation, and in the second mode it moves in the opposite direction to the rotation (Fig. 4).

A particular solution of Eqs. (8), depending on the disturbing force, represents the forced vibrations of the system, which is expressed as follows:

$$
z_{2}=d \sin p t+d_{1} \sin \omega^{*} t, \quad y_{2}=b \cos p t+b_{1} \cos \omega^{*} t+\frac{F_{r} l_{1}}{k_{y} l^{2}},
$$

where

$$
\begin{aligned}
& b=\frac{M_{z} p A \omega_{b}-M_{y}\left(k_{z} l^{2}-J_{0} p^{2}\right)}{p^{2} A^{2} \omega_{b}^{2}-\left(k_{y} l^{2}-J_{0} p^{2}\right)\left(k_{z} l^{2}-J_{0} p^{2}\right)}, \\
& d=\frac{M_{z}\left(k_{y} l^{2}-J_{0} p^{2}\right)-M_{y} p \omega_{b}}{\left(k_{z} l^{2}-J_{0} p^{2}\right)\left(k_{y} l^{2}-J_{0} p^{2}\right)-p^{2} A^{2} \omega_{b}^{2}}, \\
& b_{1}=\frac{-F_{a} l_{1}\left(k_{z} l^{2}-J_{0} \omega^{* 2}\right)}{A^{2} \omega_{b}^{2} \omega^{* 2}-\left(k_{y} l^{2}-J_{0} \omega^{* 2}\right)\left(k_{z} l^{2}-J_{0} \omega^{* 2}\right)}, \\
& d_{1}=\frac{-F_{a} l_{1} A \omega_{b} \omega^{*}}{\left(k_{z} l^{2}-J_{0} \omega^{* 2}\right)\left(k_{y} l^{2}-J_{0} \omega^{* 2}\right)-A^{2} \omega_{b}^{2} \omega^{* 2}} .
\end{aligned}
$$

Adding the general (Eq. (9)) and the partial (Eq. (11)) solution, a general solution of differential equations (8) for displacements $y$ and $z$ of the 
blank end was obtained, which allows an easy determination of the velocities $v_{y}$ and $v_{z}$.

Usually, in the study of steady-state vibrations the values of the components, which determine free damping vibrations, are reduced. However, it is impossible to achieve it in this case, because the operating conditions of the cutting are changed due to surface roughness.

\section{EXPERIMENTAL ANALYSIS}

\subsection{Experimental test of the spring constant of the lathe}

The accuracy of the accepted models was tested on the lathe $1 \mathrm{~K} 62$.

During the theoretical analysis, calculation accuracy depends on both the degree of fitness of the accepted models of the real system and on how accurately mechanical characteristics of the lathe are determined. One of these characteristics is the spring constant of the lathe. The latter is determined by the static loading of its elements, connected with the workpiece and the cutter. The direction and points of application of the force are selected according to typical situations of the details on the specific lathe. To decrease the influence of the resistance force on the test results, static rigidity was measured with weak vibrations of the lathe, excited by running the electric motor and other mechanisms without a load. Two load positions were involved in the test (Fig. 5).

The system was loaded gradually with a step of $100 \mathrm{~N}$ by means of the dynamometer, but the displacements with an accuracy of $0.002 \mu \mathrm{m}$ were registered by the indicators at three points: on the tailstock (indicator 1), on the spindle (indicator 2) and on the blank (indicator 3). Figure 6 shows the results of the statistical analysis of the experiment data in the form of correlation functions, where the coefficient of direct regression is the unknown rigidity.

The coefficient of correlation was obtained close to a unit that indicates a linear correlation function between the load and the displacement.
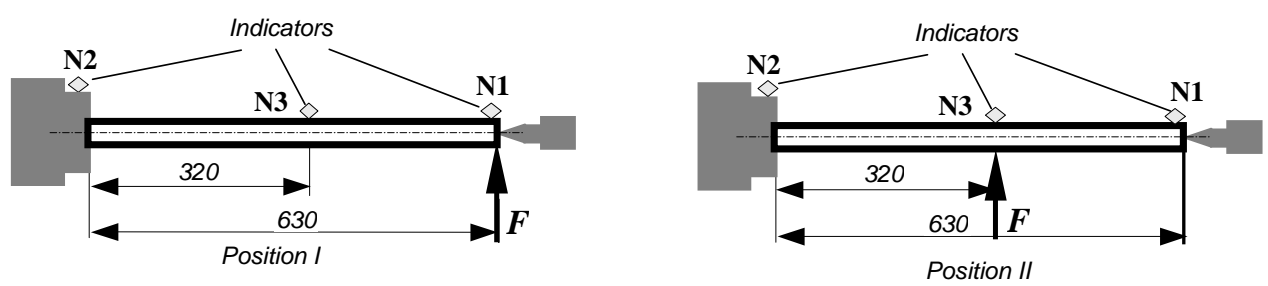

Fig. 5. Schema of vertical and horizontal rigidity measurements of the lathe. 


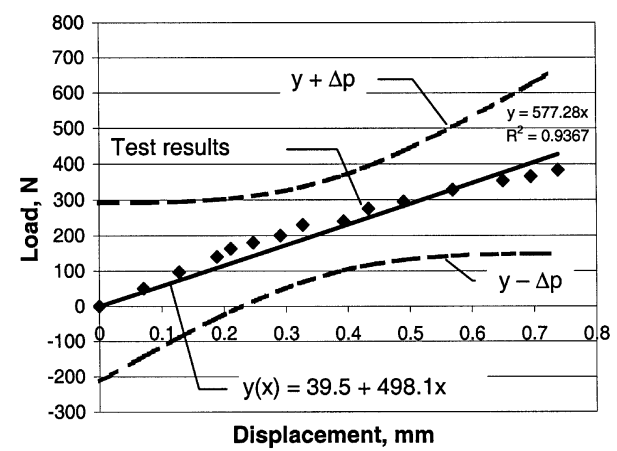

(a)

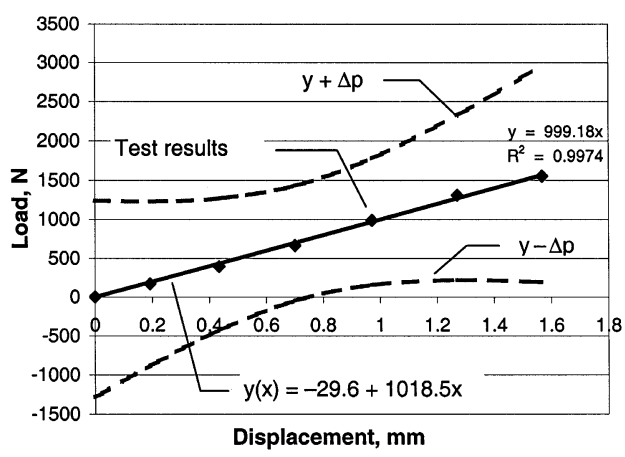

(b)

Fig. 6. Correlation function between the load and static displacement for horizontal (a) and vertical (b) loads.

\subsection{Experimental analysis of the vibration on idling of the lathe}

On the basis of static experiments, it was concluded that the blank can be considered an ideal solid body hinged in the headstock and elastically hinged in the backstock. Therefore, the system with one degree of freedom for vibration analysis in the horizontal plane (Fig. 1, a) and that with two degrees of freedom (Fig. 1, b) are admissible.

The vibration analyser SigLab 20.22A was used for measurements with special software in MATLAB, designed for multichannel investigations of vibroacoustic signals in the frequency band from $2 \mathrm{~Hz}$ to $50 \mathrm{kHz}$. Piezoelectric accelerometers KISTLER 870B10 and KISTLER 8702B50 with a sensitivity of $50 \mu \mathrm{v} / \mathrm{g}$ were used as transducers. In addition, a vibrometer, collector data PICOLOG CMVL 10, was used for measurements in the frequency band of $30 \mathrm{~Hz}$ to $10 \mathrm{kHz}$. The piezoelectric accelerometers were installed on the blank and to the lathe base.

\subsubsection{Experimental test without rotation of the blank}

Figure 7 shows the results of vibration measurements in the horizontal and vertical planes; theoretical reference results of vibration velocity according to Eq. (3) are also given.

The experimental results satisfactorily coincide with the theoretical ones in certain frequency ranges. However, an increase in the frequency leads to a gradual increase in discrepancies between the theoretical and experimental results.

That is explained by a certain inadequacy of the accepted dynamic model with one degree of freedom. On the other hand, there were too few accelerometers installed onto the blank. The transducer did not record the vibrations, if it was located in a node of normal modes (for example, at horizontal vibrations of frequencies 188.75 and $405.00 \mathrm{~Hz}$ (Fig. 7, a) and vertical vibrations with frequencies 


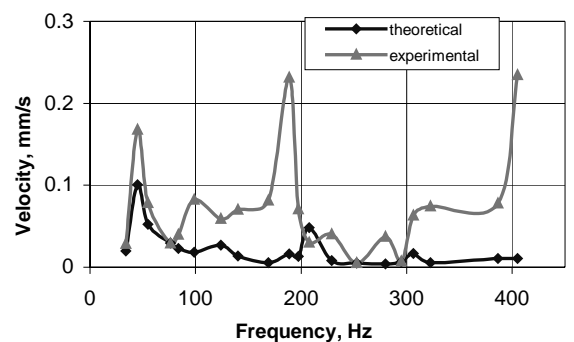

(a)

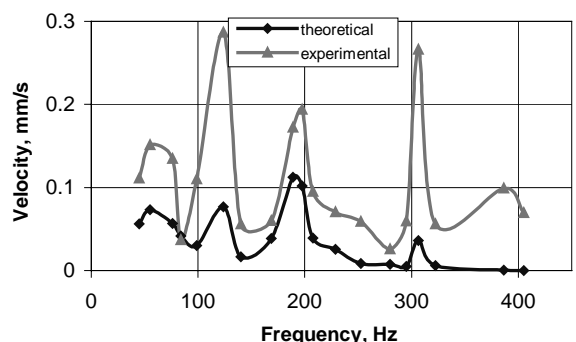

(b)

Fig. 7. Experimental and theoretical results about horizontal (a) and vertical (b) vibrations of the blank without rotation.

123.75 and $306.00 \mathrm{~Hz}$, were the largest differences between experimental and theoretical results, occurred).

\subsubsection{Experimental test in the case of the blank rotation}

A similar experiment was conducted in the case of the rotating blank. Tests were carried out at different frequencies of the rotation of the spindle. In contrast to the previous test, one of the piezoindicators was installed on the tailstock. That slightly distorted the measurement results, but the overall picture remained unaltered. It was confirmed by measurements with the vibrometer PICOLOG, which was in contact with the surface of the rotating blank. Test results in horizontal and vertical planes and the corresponding theoretical results of the vibration velocity according to Eqs. (3) and (9-12) with gyroscopic forces are shown in Fig. 8. The frequency of the rotation of the spindle was $1600 \mathrm{rpm}$. As can be seen in Fig. 8, the theoretical results, obtained taking into account gyroscopic forces, are in agreement with the experimental results.

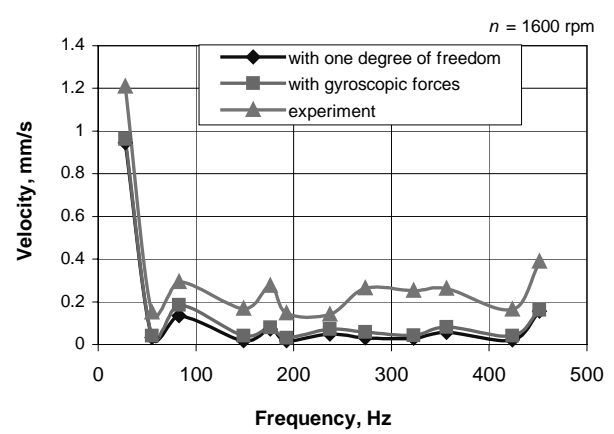

(a)

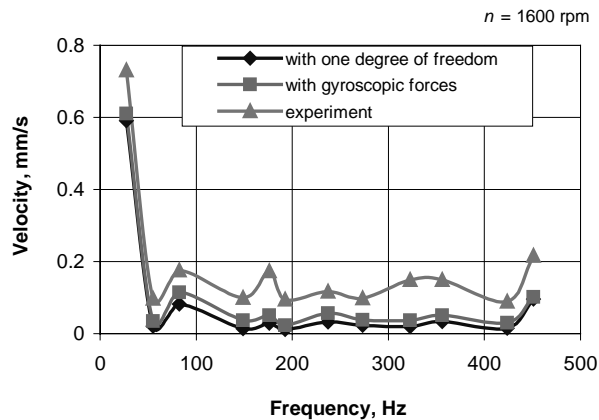

(b)

Fig. 8. Experimental and theoretical results about horizontal (a) and vertical (b) vibrations in the case of the blank rotation with gyroscopic forces. 


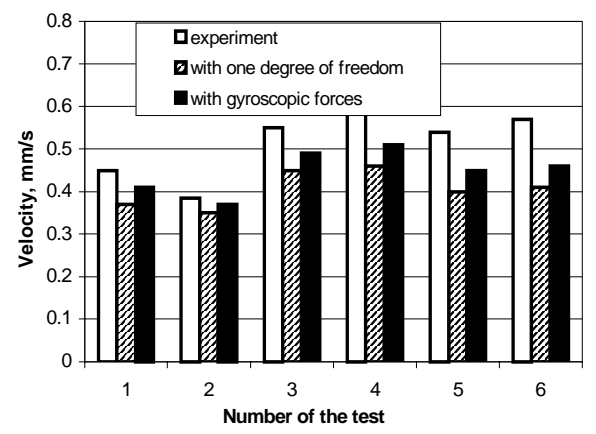

(a)

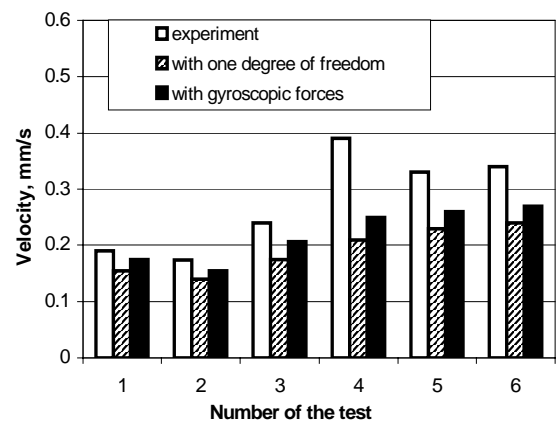

(b)

Fig. 9. Comparative analysis of experimental and theoretical results about horizontal (a) and vertical (b) vibrations by cutting.

\subsection{Measuring of vibrations by cutting}

Experimental measurements were performed at different cutting speeds, feeds and depths of the cut. Test results and results of the calculation using Eqs. (6)-(7) and (11)-(13), taking into account gyroscopic forces, are presented in Fig. 9. After every cutting, surface roughness was measured with the profilograph Surftronic 3+. The amplitude $F_{a}$ of the variable component of the cutting force in Eq. (4) was taken according to the experimentally measured roughness. The analysis of the roughness measurement data confirmed the accuracy of the calculation model. Surface roughness parameters of the blank quite satisfactorily agree with the data of the theoretical investigation. Like in the previous case, the results of calculation with gyroscopic forces according to Eqs. (11)-(13) are in better agreement with the experimental results.

\section{CONCLUSIONS}

The analysis of the roughness measurement data confirms the accuracy of the dynamic calculation model. Surface roughness parameters of the blank quite satisfactorily agree with the corresponding data of the theoretical investigation. The calculation model with two degrees of freedom was used to analyse the influence of gyroscopic forces on surface roughness. The results of experimental and theoretical investigations show that this model is adequate.

\section{REFERENCES}

1. Hakansson, L. Adaptive Active Control of Machine-Tool Vibration in a Lathe. Department of Production and Materials Engineering, Lund University, KFS AB, Lund, 1999.

2. Gaponkin, V. A., Lukashev, L. K. and Suvorov, T. G. Cutting Process, Metal-cutting Instrument and Lathes. Mashinostroenie, Moscow, 1995 (in Russian). 
3. Arshanski, M. M. and Tcherbakov, V. P. Vibrodiagnostics and Control of the Processing Accuracy on Metal-cutting Lathes. Mashinostroenie, Moscow, 1998 (in Russian).

4. Sharma, V. S., Sharma, S. K. and Sharma A. K. Knowing various wear states of the turning tool using acoustic emissions. In Proc. $20^{\text {th }}$ International Conference on CAD/CAM, Robotics and Factories of the Future (Marquez, A., ed). San Cristobal, Venezuela, 2004, 168-177.

5. Bayard, O. Investigation of Forces and Contact Area for Modelling Turning Process. Thesis. Chair of Production Engineering, Department of Production Engineering, The Royal Institute of Technology, Stockholm, 2003.

6. Astakhov, V. P. Metal Cutting Mechanics. CRC Pr., Boca Raton, 1999.

7. Klyuev, V. V., Nachapetjan, E. G. and Scherbakov, V. V. Methods for nondestructive testing and diagnostics of automatic equipment and technological systems of machines. In Manufacturing Technologies for Machines of the Future (Dashchenko, A., ed). Springer, Berlin, 2003, 683-719.

8. Aryassov, G., Pappel, T. and Gromova, S. Effect of vibration on accuracy of processed details when cutting. In Proc. $20^{\text {th }}$ International Conference on Mathematical Modelling in Mechanics of Solids and Structures by Boundary \& FEM. St. Petersburg, 2003, vol. 2, 51-57.

\title{
ACNOWLEDGEMENT
}

This work was supported by Estonian Science Foundation (grants Nos. 5161 and 5636).

\section{Täiustatud dünaamilised mudelid töötlustäpsuse hindamiseks treipinkides}

\author{
Gennadi Aryassov, Tauno Otto ja Svetlana Gromova
}

Artiklis kirjeldatakse treipingis tekkivate vibratsioonide mõju töötlustäpsusele ja töödeldud detailide pinnakaredusele. Esitatakse ühe ja kahe vabadusastmega arvutusskeemid, kus töödeldava tooriku vibratsioone on kirjeldatud spindlisse šarniirselt kinnitatud ja tagapukist elastselt toetatud jäiga keha võnkumistena. Eksperimentaalsete tulemuste saamiseks viidi mõõtmised läbi universaaltreipinkides erinevatel lõikekiirustel, ettenihetel ja lõikesügavustel. Profilograafiga registreeritud mõõtmistulemuste analüüs kinnitab töös esitatud arvutusmudeli täpsust ning toorikul mõõdetud pinnakareduse parameetrid langesid rahuldavalt kokku teoreetiliste tulemustega. Güroskoopiliste jõudude mõju uurimiseks pinnakaredusele kasutati kahe vabadusastmega arvutusmudelit. Eksperimentaalsete ja arvutuslike tulemuste võrdlus kinnitab mudeli adekvaatsust. 